\title{
OPTIMASI \\ MODEL KLASIFIKASI C4.5 DAN PARTICLE SWARM OPTIMIZATION UNTUK PREDIKSI SISWA BERMASALAH
}

\author{
Hayati Noor \\ Fakultas Teknologi Informasi \\ Universitas Islam Kalimantan Muhammad Arsyad Al Banjari Banjarmasin \\ email: adhienk.athie@gmail.com
}

\begin{abstract}
Abstrak
Sekolah adalah lembaga pendidikan kedua bagi seorang anak yang memiliki peranan sangat strategis yang akan menjadi pusat-pusat kegiatan pendidikan untuk menumbuhkan dan mengembangkan potensi anak sebagai makhluk individu, sosial, susila dan religius. Deteksi dini dapat juga mendeteksi siswa dengan masalah belum serius, sehingga pihak sekolah memberikan dukungan dan perhatian yang tepat sebelum kondisi ini memburuk. Dalam menentukan apakah seorang siswa bermasalah maka pendidik (orang tua, wali siswa, wali kelas, dan guru) harus memperhatikan kekhasan perilaku anak dan perlu memahami tahapan perkembangan anak dalam segala aspek. Berdasarkan kondisi tersebut teknik data mining yang tepat digunakan adakah klasifikasi. Salah satu teknik klasifikasi data mining adalah C4.5. Dalam penelitian ini, membandingkan algoritma C4.5 dengan C4.5 berbasis PSO (Particle Swarm Optimazion) yang diterapkan pada data siswa bermasalah. C4.5 dan Particle Swarm Optimization menjadi lebih baik dalam memprediksi nilai akurasi daripada menggunakan hanya metode C4.5 saja, yang mampu meningkatkan nilai akurasi cukup tinggi yaitu sebesar 35.7\%. Optimasi Decision Tree C4.5 dapat diterapkan untuk prediksi siswa berpotensi bermasalah dengan tingkat akurasi 99,08\%. Dalam prediksi siswa berpotensi bermasalah, akurasi optimasi Algoritma C4.5 dan Particle Swarm Optimization lebih baik dari pada Algoritma decision Tree C.4.5 saja, dengan perbedaan yang cukup besar.
\end{abstract}

Keyword : Siswa bermasalah, data mining, C4.5. PSO,

\section{PENDAHULUAN}

Lembaga penelitian telah menunjukkan bahwa identifikasi awal, penilaian, dan intervensi untuk masalah emosional dan perilaku anak-anak sampai remaja dapat membantu mencegah masalah yang lebih serius, seperti kegagalan pendidikan, penyalahgunaan narkoba, keterlibatan dalam tindak kriminal, atau bunuh diri [1]. Data terbaru menunjukkan bahwa, pada masa tertentu, antara 5 dan 9 persen dari anak-anak dan pengalaman remaja mengalami masalah emosional yang serius, yang dapat menghambat kemampuan mereka untuk menjalani kehidupan yang penuh dan produktif [2].

Deteksi dini dapat membantu mengurangi dampak yang signifikan terhadap anak-anak dan remaja yang mungkin mengalami masalah perilaku dan kebiasaan bermasalah. Deteksi dini dapat juga mendeteksi siswa dengan masalah belum serius, sehingga pihak sekolah memberikan dukungan dan perhatian yang tepat sebelum kondisi ini memburuk. Dengan demikian, prediksi siswa bermasalah adalah langkah pertama dalam deteksi dini, mengenali masalah emosional dan perilaku dan memberikan bantuan pada titik awal dan efektif; jika masalah terdeteksi, penilaian dan evaluasi lebih lanjut dapat menentukan perhatian dan layanan yang sesuai yang diperlukan [3].

Dalam menentukan apakah seorang siswa bermasalah maka pendidik (orang tua, wali siswa, wali kelas, dan guru) harus memperhatikan kekhasan perilaku anak dan perlu memahami tahapan perkembangan anak dalam segala aspek. Pemahaman tersebut dapat membantu menganalisis dan mengelompokkan anak pada kategori bermasalah atau tidak. Apakah frekuensi tingkah laku yang menyimpang tersebut terlihat setiap waktu? Apakah perilaku tersebut mengganggu aktivitas 
siswa baik di dalam maupun di luar kelas? Jika tingkah laku tersebut tidak diatasi dengan segera apakah akan menimbulkan masalah dalam perkembangan anak secara menyeluruh? Jika semua pertanyaan tersebut dijawab "ya", maka besar kemungkinan anak tersebut bermasalah. Daftar kekhasan perilaku dan kebiasaan ini telah buat secara sistematis, di antaranya Student Risk Screening Scale (SRSS) dan Kredit Point Sanksi Pelanggaran tata Tertib Siswa

Data Point Siswa berdasarkan daftar cek kredit point tersedia, namun perlu suatu proses untuk mendapatkan informasi yang berguna sesuai dengan tujuan tertentu. Proses ini dapat menggunakan klasifikasi prediksi [4]. Tujuannya agar dapat diketahui pola-pola universal dari data yang ada. Faktor-faktor yang dapat mempengaruhi perilaku siswa inilah yang akan dianalisa dan di klasifikasi untuk kemudian di prediksi sehingga membentuk kelompok-kelompok yang memiliki kesamaan tersembunyi dari data yang telah dianalisa [5]. Jadi, klasifikasi merupakan suatu proses menemukan kumpulan pola atau fungsi yang mendeskripsikan serta memisahkan kelas data yang satu dengan yang lainnya untuk menyatakan objek tersebut masuk pada kategori tertentu yang sudah ditentukan [6].

Klasifikasi data dapat digunakan untuk mengetahui tingkat hubungan antar data tersebut adalah dengan metode decision tree. Metode ini populer karena mampu melakukan klasifikasi sekaligus menunjukkan hubungan antar atribut. Algoritma klasifikasi decision tree C4.5, C5.0, CART, daan CHAID dapat digunakan untuk menganalis kredit [7], penjualan dan sebarannya [8]. Hongxing $\mathrm{He}$, dkk membandingkan algoritma C4.5 dengan Logistic Regression serta Risk Pattern Mining (RPM) ketika mempelajari faktor-faktor yang menyebabkan untuk memutuskan apakah menyusui bayi baru lahir secara langsung atau tidak menyusui bayi yang baru lahir. Mereka menyatakan bahwa C4.5 lebih baik dibandingkan logistic regression serta Risk Pattern Mining.

Berdasarkan latar tersebut, dalam penelitian ini, algoritma C4.5 dan Particle Swarm Optimization akan digunakan untuk membangun model klasifikasi prediksi siswa bermasalah dan dibandingkan dengan hasil algoritma CART.

\section{Perumusan Masalah}

Berdasarkan latar belakang di atas, rumusan masalah dalam bentuk pertanyaan penelitian (research questions), adalah: "Bagaimana model algoritma klasifikasi C4.5 dan Particle Swarm Optimization dapat membantu pendidik memprediksi siswa bermasalah dengan akurat?"

\section{Tujuan Penelitian}

Berdasarkan latar belakang dan rumusan masalah diatas, maka penelitian ini bertujuan untuk mengoptimasi penerapan algoritma klasifikasi C4.5 dan Particle Swarm Optimization untuk prediksi siswa bermasalah.

\section{Manfaat Penelitian}

a. Manfaat praktis dari hasil penelitian ini adalah diharapkan agar dapat menjadi referensi untuk penerapan model klasifikasi untuk prediksi.

b. Manfaat teoritis dari hasil penelitian ini diharapkan dapat membantu pendidik (orang tua siswa, wali siswa, wali kelas, dan guru) dalam memperhatikan perkembangan pendidikan dan karakter siswa.

c. Manfaat kebijakan yaitu diharapkan agar metode klasifikasi untuk prediksi mampu menjadi deteksi dini siswa bermasalah dan dapat mempengaruhi dan mengembangkan pola asuh terhadap siswa.

\section{METODE PENELITIAN}

Metode penelitian yang dilakukan adalah metode penelitian eksperimen, dengan tahapan penelitian sebagai berikut :

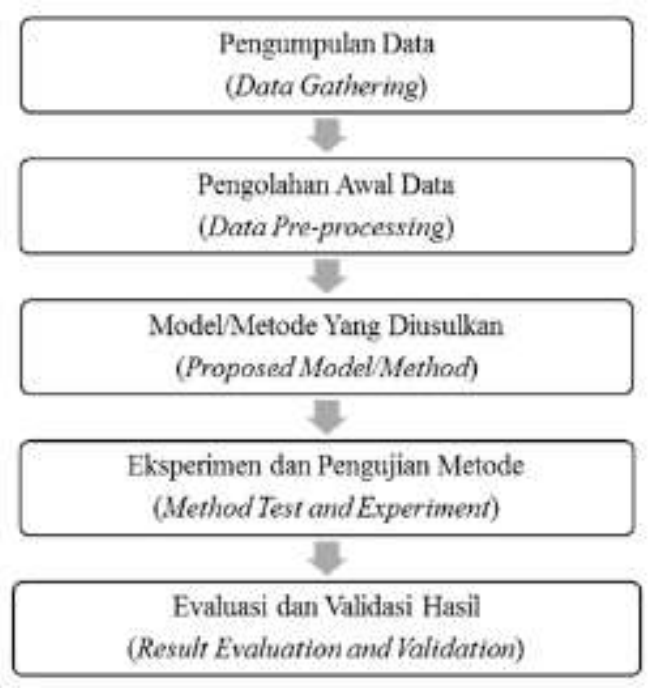




\section{Gambar 2.1 Tahapan Metode Penelitian Eksperimen}

Data yang digunakan adalah data yang diperoleh dari SMAN 2 Banjarbaru. Pada proses awal data tersebut diolah kembali untuk menentukan objek yang akan dijadikan bahan pengujian. Setelah dianalisa dan diolah, data kemudian diuji dengan menggunakan metode yang telah ditentukan agar dapat diketahui hasil dari pengujian data tersebut.

\section{Pengumpulan Data}

Data didapatkan dari Sekolah Menengah Atas Negeri 2 Banjarbaru. Data diambil adalah tahun ajaran 2016-2017 siswa kelas XI IPA dan IPS.

\section{- Data Sekunder}

Data siswa meliputi: Nama, NIPD, Tangal

Lahir, Jenis Kelamin, Umur, Kelas, Asal

Sekolah, Agama, Anak Ke, Jumlah

Saudara, Status Anak, Tempat Belajar,

Nama Ayah, Tahun Lahir Ayah, Jenjang

Pendidikan Ayah, Pekerjaan Ayah,

Penghasilan Ayah, Nama Ibu, Tahun Lahir

Ibu, Jenjang Pendidikan Ibu, Pekerjaan Ibu,

Penghasilan Ibu, Poin. Jadi ada 23 atribut.

\section{- Data Primer}

Data primer yang digunakan adalah data hasil komputasi algoritma klasifikasi.

\section{Pengolahan Data Awal}

Data yang dikumpulkan kemudian dipilah dan disiapkan untuk menghasilkan data yang siap untuk diproses oleh Algoritma. Data siswa meliputi: NIPD, Umur, Jenis Kelamin, Kelas, Asal Sekolah, Agama, Anak ke, Jumlah Saudara, Status Anak, Tempat Belajar, Umur Ayah, Pendidkan Ayah, Pekerjaan Ayah, Penghasilan Ayah, Umur Ibu, Pendidikan Ibu, Pekerjaan Ibu, Penghasilan Ibu, Poin. Jadi hanya 19 atribut.

Data yang pilih adalah data yang seluruh attribut yang diperlukan lengkap (22 atribut). Jadi data siswa yang tidak lengkap, otomatis diabaikan.

\section{Metode/Model yang diusulkan:}

Metode yang digunakan adalah perbandingan akurasi prediksi yang dihasilkan oleh Algoritma Klasifikasi C4.5 dan Particle Swarm Optimization. Data diproses menggunakan C4.5 dan Particle Swarm
Optimization yang diaplikasikan menggunakan RapidMiner.

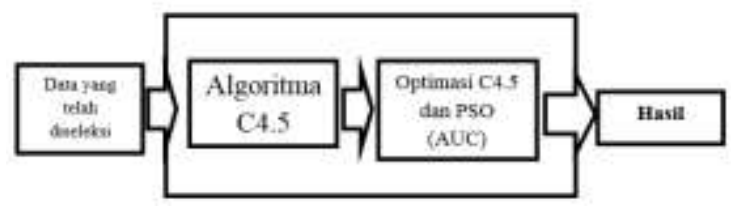

Gambar 2.2 Metode yang diusulkan

\section{Eksperimen dan Pengujian Model/Metode}

Data akan diproses oleh model C4.5 kemudian dicatat akurasinya. Kemudian, dilakukan beberapa perubahan setting, dan hasilnya dicatat. Kemudian data yang sama akan diproses secara sama dengan model Optimasi C4.5 dan PSO, kemudian hasilnya dibandingkan.

\section{Evaluasi dan Validasi}

Evaluasi dan validasi dilakukan dengan mengamati hasil prediksi dibandingkan dengan data awal yang diolah. Hasil akan diperoleh setelah proses eksperimen dan pengujian dilaksanakan.

Pengukuran kinerja dilakukan dengan menghitung rata-rata error yang terjadi melalui besaran akurasi (AUC). Semakin besar akurasi menyatakan semakin dekat nilai prediksi dengan nilai sebenarnya. Dengan demikian dapat diketahui tingkat akurasi algoritma C4.5 yang dioptimasi dengan PSO. Sehingga dapat diketahui apakah algoritma C4.5 dan PSO dapat digunakan untuk memprediksi anak berpotensi bermasalah di SMA khususnya SMAN 2 Banjarbaru.

\section{HASIL DAN PEMBAHASAN}

\section{Hasil Eksperimen dan Pengujian Metode Eksperimen C4.5}

Untuk desain eksperimen dan pengujian penelitian dengan menggunakan C4.5 adalah seperti gambar 3.1 :

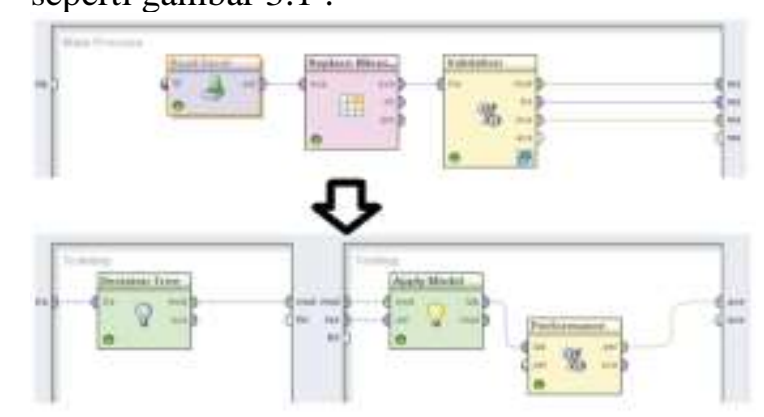

Gambar 3.1 Desain eksperimen C4.5 
Pada gambar 4.1 di atas terlihat desain model eksperimen yang digunakan peneliti untuk memperoleh tingkat akurasi prediksi siswa bermasalah berpotensi bermasalah dengan menggunakan algoritma $\mathrm{C} 4.5$, data yang kosong dhilangkan dengan menggunakan replace missing. Pengujian model dengan merubah nilai validasinya. Pengujian data nilai validasi dimulai $2,3,4,5,6,7,8,9$ dan 10 kemudian dievaluasi dan dibandingkan dengan beberapa algoritma lain dengan hasil sebagai berikut :

Tabel 3.1 Hasil Pengujian C4.5

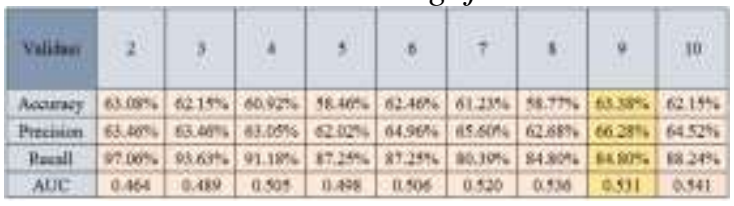

Dari hasil percobaan seperti tabel 3.1 hasil pengujian sebanyak 9 percobaan dengan hasil tingkat akurasi tertinggi sebesar $63.38 \%$ dengan nilai validasi $=9$.

\section{Hasil Akurasi C4.5 Nilai Validasi 2}

Tahap pertama pengujian dilakukan dengan data nomer akurasi validasi 2 . Ketika diimplementasikan menghasilkan data sebagai berikut :

Tabel 3.2 Hasil Akurasi C4.5

\begin{tabular}{|c|c|c|c|}
\hline \multicolumn{4}{|c|}{ atomarar $63.05 \%+\%, 0.136$ (mikrot $63.08 \%)$} \\
\hline & $\begin{array}{c}\text { Troe } \\
\text { berpotensi Bermasalah }\end{array}$ & $\begin{array}{c}\text { true } \\
\text { Tides: Bermasalah }\end{array}$ & elines preciácich \\
\hline pred. Berpotensi Bermasaind & 7 & 6 & $33.85 \%$ \\
\hline Prod Tidak Bermanaliah & 114 & 198 & 63.465 \\
\hline Elan recall & $5.79 \%$ & $97.06 \%$ & \\
\hline
\end{tabular}

Dari hasil pengujian pada tabel 3.2 menggunakan nilai validasi dengan data original tersebut didapatkan nilai akurasi $63.08 \%$.

\section{Hasil Akurasi C4.5 Nilai Validasi 3}

Tahap kedua pengujian dilakukan dengan data nomer akurasi validasi 3. Ketika di implementasikan menghasilkan data sebagai berikut :

Tabel 3.3 Hasil Akurasi C4.5

\begin{tabular}{|c|c|c|c|}
\hline & $\begin{array}{c}\text { Trat } \\
\text { berpocosai Bemanalih }\end{array}$ & $\begin{array}{c}\text { Trus } \\
\text { Tidak Hernimalah }\end{array}$ & clisan precinist. \\
\hline prod. Berpoterai Bermasalah & 11 & i) & $45.53 \%$ \\
\hline Pred Tidak Betmaaslah & 110 & 191 & $63.46 \%$ \\
\hline dan reall & $9.03 \%$ & 93,635 & \\
\hline
\end{tabular}

Dari hasil pengujian pada tabel 3.3 menggunakan nilai validasi dengan data original tersebut didapatkan nilai akurasi $62.15 \%$.

\section{Hasil Akurasi C4.5 Nilai Validasi 4}

Tahap ketiga pengujian dilakukan dengan data nomer akurasi validasi 4 . Ketika di implementasikan menghasilkan data sebagai berikut :

\section{Tabel 3.4 Hasil Akurasi C4.5}

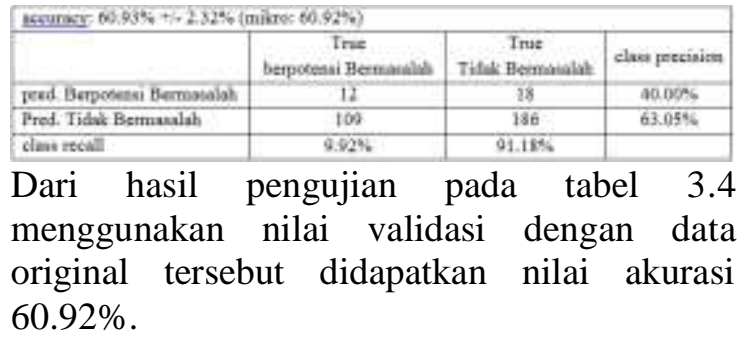

\section{Hasil Akurasi C4.5 Nilai Validasi 5}

Tahap keempat pengujian dilakukan dengan data nomer akurasi validasi 5. Ketika diimplementasikan menghasilkan data sebagai berikut :

\section{Tabel 3.5 Hasil Akurasi C4.5}

\begin{tabular}{|c|c|c|c|}
\hline 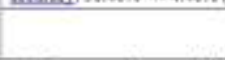 & $\begin{array}{c}\text { true } \\
\text { temponasi Denasalah }\end{array}$ & $\begin{array}{c}\text { Trre } \\
\text { Titak Demasalah }\end{array}$ & chan presicion \\
\hline 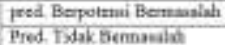 & 12 & 26 & 31.585 \\
\hline 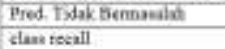 & 104 & 178 & 02025 \\
\hline 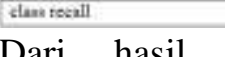 & $9.52 \%$ & $87.25 \%$ & \\
\hline $\begin{array}{l}\text { Dari hasil } \\
\text { menggunakan } \\
\text { original terse } \\
58.46 \% \text {. }\end{array}$ & $\begin{array}{l}\text { pengujian } \\
\text { nilai val }\end{array}$ & $\begin{array}{ll}\text { pada } & \text { tal } \\
\text { asi } & \text { deng } \\
\text { xan nilai }\end{array}$ & $\begin{array}{l}\text { el } \\
\text { an }\end{array}$ \\
\hline
\end{tabular}

\section{Hasil Akurasi C4.5 Nilai Validasi 6}

Tahap kelima pengujian dilakukan dengan data nomer akurasi validasi 6. Ketika diimplementasikan menghasilkan data sebagai berikut :

\section{Tabel 3.6 Hasil Akurasi C4.5}

\begin{tabular}{|c|c|c|c|}
\hline & & & \\
\hline & bespotensi Blemsuralat & Tilak Bernasalah & slens peteisioce \\
\hline Frad: & 25 & 26 & 59.0256 \\
\hline Prod. Tíak Bennasalih & ss & 178 & $64.90 \%$ \\
\hline tenar reall & $20.00 \%$ & $5725 \%$ & \\
\hline $\begin{array}{l}\text { Dari hasil } \\
\text { menggunakan } \\
\text { original tersel } \\
62.46 \% \text {. }\end{array}$ & $\begin{array}{l}\text { pengujian } \\
\text { nilai vali }\end{array}$ & $\begin{array}{ll}\text { oada } & \text { tal } \\
\text { asi } & \text { deng } \\
\text { an } & \text { nilai }\end{array}$ & $\begin{array}{l}\text { el } 3.6 \\
\text { in data } \\
\text { akurasi }\end{array}$ \\
\hline
\end{tabular}

\section{Hasil Akurasi C4.5 Nilai Validasi 7}

Tahap keenam pengujian dilakukan dengan data nomer akurasi validasi 7. Ketika diimplementasikan menghasilkan data sebagai berikut :

Tabel 3.7 Hasil Akurasi C4.5 


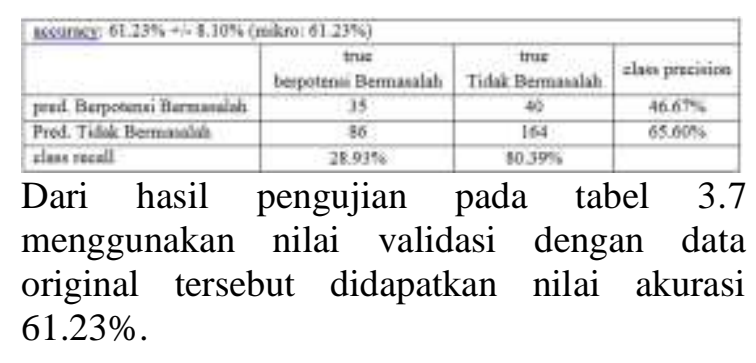

\section{Hasil Akurasi C4.5 Nilai Validasi 8}

Tahap ketujuh pengujian dilakukan dengan data nomer akurasi validasi 8 . Ketika diimplementasikan menghasilkan data sebagai berikut :

Tabel 3.8 Hasil Akurasi C4.5

\begin{tabular}{|c|c|c|c|}
\hline & $\begin{array}{c}\text { true } \\
\text { topoteni Bermalalat. }\end{array}$ & $\begin{array}{c}\text { mus } \\
\text { Triak Bermuatiath }\end{array}$ & Lan procision \\
\hline prod Berpotens Bermiasalah & Iix & 31 & $x>34$ \\
\hline Pred Tidok Berstanaliah & 103 & 173 & $62.63 \mathrm{~F}$ \\
\hline chan resall & $148 \mathrm{BW}$ & $84.501 \times$ & \\
\hline
\end{tabular}

Dari hasil pengujian pada tabel 3.8 menggunakan nilai validasi dengan data original tersebut didapatkan nilai akurasi $58.77 \%$.

\section{Hasil Akurasi C4.5 Nilai Validasi 9}

Tahap kedelapan pengujian dilakukan dengan data nomer akurasi validasi 9. Ketika diimplementasikan menghasilkan data sebagai berikut :

Tabel 3.9 Hasil Akurasi C4.5

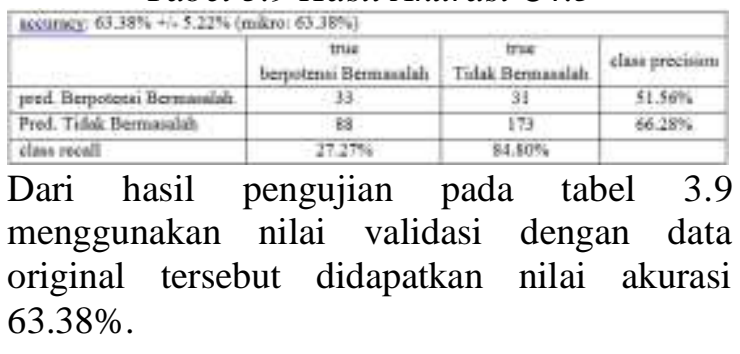

\section{Hasil Akurasi C4.5 Nilai Validasi 10}

Tahap kesembilan pengujian dilakukan dengan data nomer akurasi validasi 10. Ketika diimplementasikan menghasilkan data sebagai berikut :

\section{Tabel 3.10 Hasil Akurasi C4.5}

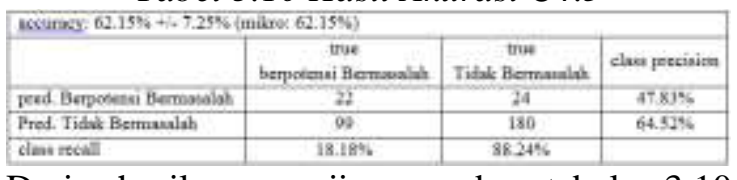

Dari hasil pengujian pada tabel 3.10 menggunakan nilai validasi dengan data original tersebut didapatkan nilai akurasi $62.15 \%$.

\section{Eksperimen Optimasi C4.5 dan Particle Swarm Optimization}

Untuk desain eksperimen dan pengujian penelitian dengan menggunakan C4.5 berbasis Particle Swarm Optimization (PSO) adalah seperti gambar 3.2 :

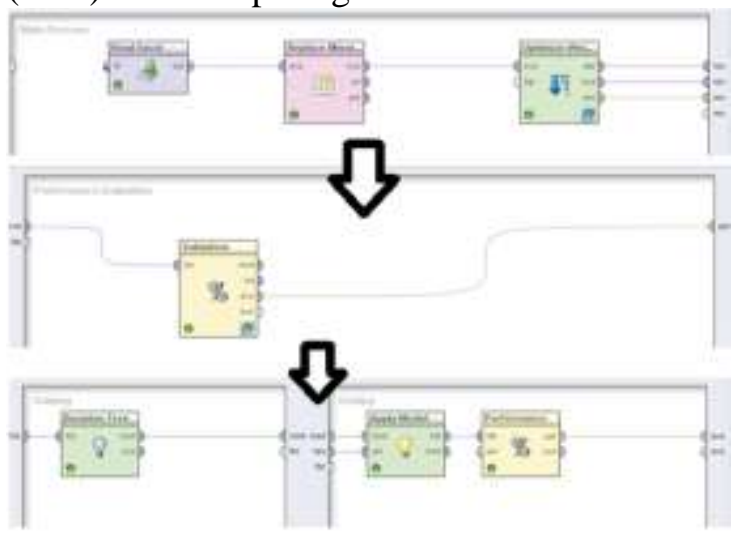

Gambar 4.2 Desain eksperimen Optimasi C4.5 dan PSO

Pada gambar 4.2 di atas terlihat desain model eksperimen yang digunakan peneliti untuk memperoleh tingkat akurasi prediksi siswa berpotensi bermasalah dengan menggunakan algoritma C4.5 dan PSO, data yang kosong dhilangkan dengan menggunakan replace missing. Algoritma PSO diterapkan untuk dapat memperoleh nilai bobot variable yang terbaik pada $\mathrm{C} 4.5$ sehingga terjadinya peningkatan akurasi. Pengujian model dengan merubah nilai validasinya. Pengujian data nilai validasi dimulai $2,3,4,5,6,7,8,9$ dan 10 kemudian dievaluasi dan dibandingkan dengan beberapa algoritma lain dengan hasil sebagai berikut :

Tabel 3.11 Hasil Pengujian optimasi C4.5 dan particle swarm optimization

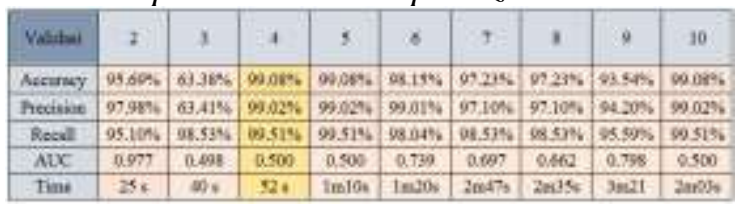

Dari hasil percobaan seperti tabel 3.11

hasil pengujian sebanyak 9 percobaan dengan hasil tingkat akurasi tertinggi sebesar $99.08 \%$ dengan nilai validasi $=4$.

\section{Hasil Optimasi C4.5 dan Particle Swarm Optimization Nilai Validasi 2}

Tahap kesepuluh pengujian dilakukan dengan data nomer akurasi validasi 2. Ketika diimplementasikan menghasilkan data sebagai berikut : 
Tabel 3.12 Hasil Optimasi C4.5 dan Particle Swarm Optimization

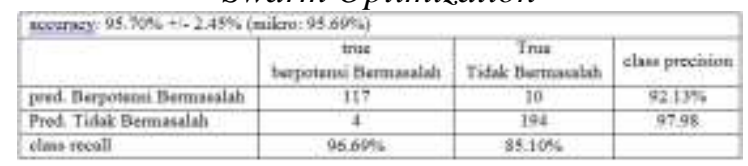

Dari hasil pengujian pada tabel 3.12 menggunakan nilai validasi dengan data original tersebut didapatkan nilai akurasi 95.69\%. Dan akurasi prediksi data berpotensi bermasalah $96,69 \%$ sedangkan tidak bermasalah hasil akurasinya $85,10 \%$.

Hasil perhitungan diatas dapat divisualisasikan dengan kurva ROC perbandingan kedua kelas bisa dilihat pada gambar 3.3 yang merupakan kurva ROC untuk optimasi algoritma C4.5 dan Particle Swarm Optimization dengan nilai validasi 2. Garis horizontal adalah false positives dan garis vertikal adalah true positives. Menghasilkan nilai AUC (Area Under Curve) sebesar 0.977 dengan nilai akurasi cukup (fair classification) pada dataset kredit point siswa berpotensi bermasalah.

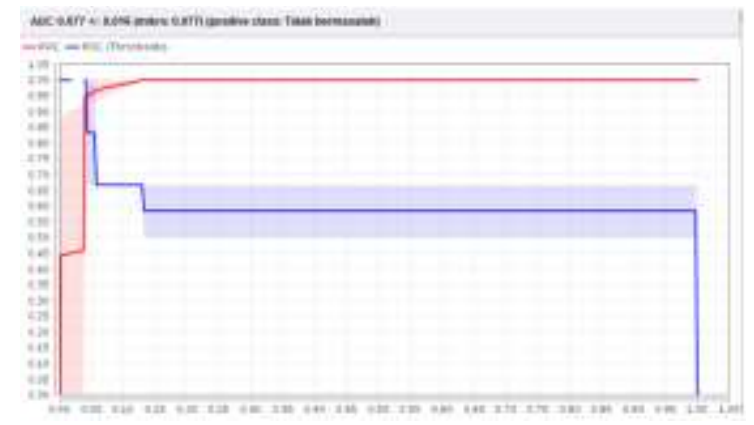

Gambar 3.3 Kurva AUC

\section{Hasil Optimasi C4.5 dan Particle Swarm Optimization Nilai Validasi 3}

Tahap kesebelas pengujian dilakukan dengan data nomer akurasi validasi 3. Ketika diimplementasikan menghasilkan data sebagai berikut :

Tabel 3.13 Hasil Optimasi C4.5 dan Particle Swarm Optimization

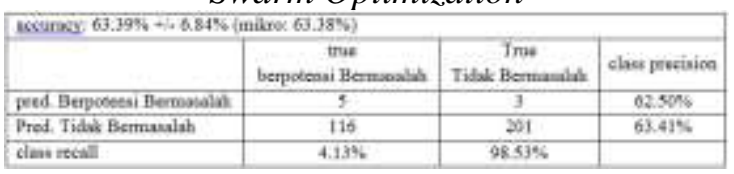

Dari hasil pengujian pada tabel 3.13 menggunakan nilai validasi dengan data original tersebut didapatkan nilai akurasi $63.38 \%$. Dan akurasi prediksi data berpotensi bermasalah $4,13 \%$ sedangkan tidak bermasalah hasil akurasinya $98,53 \%$.
Hasil perhitungan diatas dapat divisualisasikan dengan kurva ROC perbandingan kedua kelas bisa dilihat pada gambar 3.4 yang merupakan kurva ROC untuk optimasi algoritma C4.5 dan Particle Swarm Optimization dengan nilai validasi 3. Garis horizontal adalah false positives dan garis vertikal adalah true positives. Menghasilkan nilai AUC (Area Under Curve) sebesar 0.498 dengan nilai akurasi cukup (fair classification) pada dataset kredit point siswa berpotensi bermasalah.

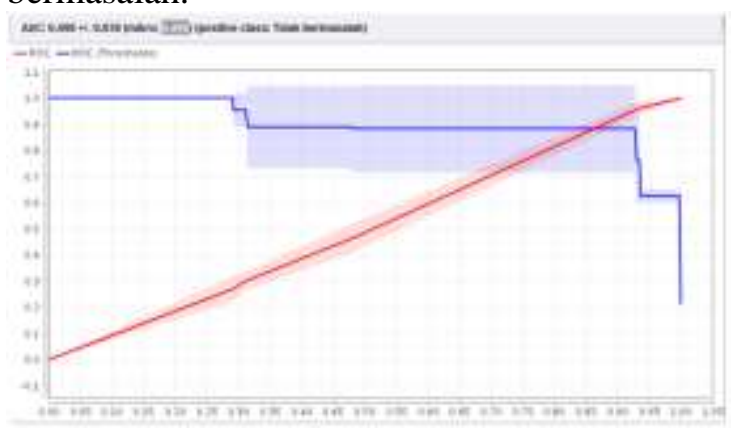

Gambar 3. 4Kurva AUC

\section{Hasil Optimasi C4.5 dan Particle Swarm Optimization Nilai Validasi 4}

Tahap keduabelas pengujian dilakukan dengan data nomer akurasi validasi 4. Ketika diimplementasikan menghasilkan data sebagai berikut :

Tabel 3.14 Hasil akurasi Optimasi C4.5 dan Particle Swarm Optimization

\begin{tabular}{|c|c|c|c|}
\hline & & Trac & \\
\hline & herpotenai Bermssalah & Tidak Bernaealah & clasi preotion \\
\hline peed Berponessi Bermanalat & 118 & 1 & $59.17 \%$ \\
\hline Wret. fidsk bemasalah & 2 & 205 & $9902 \%$ \\
\hline deatrosill & $93.35 \%$ & $90,51 \%$ & \\
\hline
\end{tabular}

Dari hasil pengujian pada tabel 3.14 menggunakan nilai validasi dengan data original tersebut didapatkan nilai akurasi 99.08\%. Dan akurasi prediksi data berpotensi bermasalah $98,35 \%$ sedangkan tidak bermasalah hasil akurasinya $99,51 \%$.

Hasil perhitungan diatas dapat divisualisasikan dengan kurva ROC perbandingan kedua kelas bisa dilihat pada gambar 3.5 yang merupakan kurva ROC untuk optimasi algoritma C4.5 dan Particle Swarm Optimization dengan nilai validasi 4 . Garis horizontal adalah false positives dan garis vertikal adalah true positives. Menghasilkan nilai AUC (Area Under Curve) sebesar 0.500 dengan nilai akurasi cukup (fair classification) pada dataset kredit point siswa berpotensi bermasalah. 


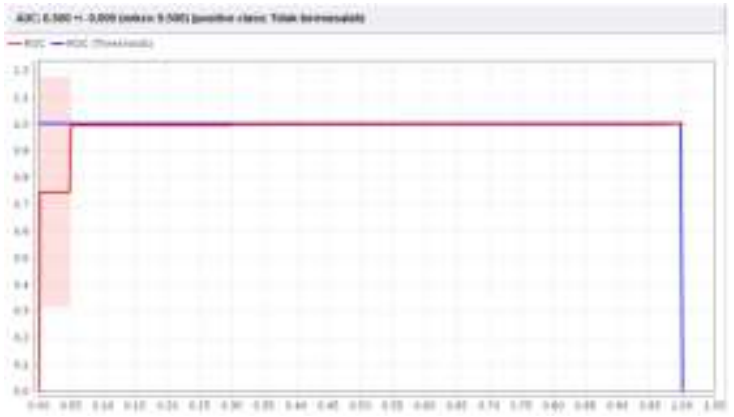

Gambar 3.5 Kurva AUC

Hasil Optimasi C4.5 dan Particle Swarm Optimization Nilai Validasi 5

Tahap ketigabelas pengujian dilakukan dengan data nomer akurasi validasi 5. Ketika diimplementasikan menghasilkan data sebagai berikut :

Tabel 3.15 Hasil Akurasi Optimasi C4.5 dan

Particle Swarm Optimization

\begin{tabular}{|c|c|c|c|}
\hline & $\begin{array}{c}\text { trü } \\
\text { bespotemai Bermasalah }\end{array}$ & $\begin{array}{c}\text { True } \\
\text { Tulak Bermanalath }\end{array}$ & dan jrecision \\
\hline prod. Hepotemin Betmassalah & 119 & 1 & $99.17 \mathrm{~S}$ \\
\hline Fred Tidak Berananinh & 2 & 203 & $90,022,9$ \\
\hline claw resall & $08.35 \%$ & क.5.51\% & \\
\hline
\end{tabular}

Dari hasil pengujian pada tabel 3.15 menggunakan nilai validasi dengan data original tersebut didapatkan nilai akurasi 99.08\%. Dan akurasi prediksi data berpotensi bermasalah $98,35 \%$ sedangkan tidak bermasalah hasil akurasinya $99,51 \%$.

Hasil perhitungan diatas dapat divisualisasikan dengan kurva ROC perbandingan kedua kelas bisa dilihat pada gambar 3.6 yang merupakan kurva ROC untuk optimasi algoritma C4.5 dan Particle Swarm Optimization dengan nilai validasi 5. Garis horizontal adalah false positives dan garis vertikal adalah true positives. Menghasilkan nilai AUC (Area Under Curve) sebesar 0.500 dengan nilai akurasi cukup (fair classification) pada dataset kredit point siswa berpotensi bermasalah.

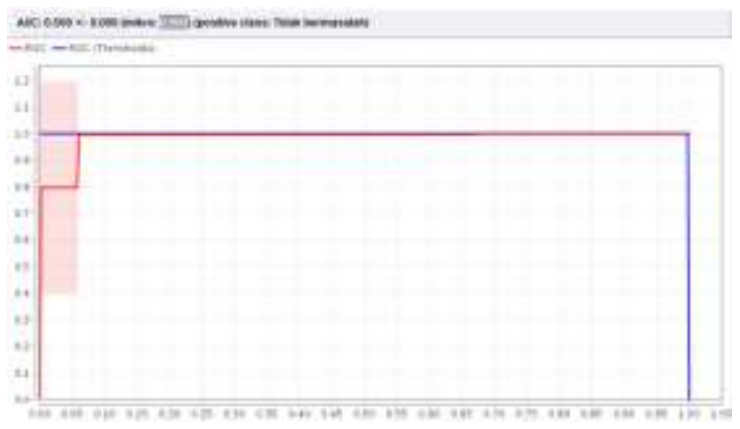

Gambar 3.6 Kurva AUC

\section{Hasil Optimasi C4.5 dan Particle Swarm Optimization Nilai Validasi 6}

Tahap keempatbelas pengujian dilakukan dengan data nomer akurasi validasi 6 . Ketika diimplementasikan menghasilkan data sebagai berikut :

Tabel 3.16 Hasil Akurasi Optimasi C4.5 dan Particle Swarm Optimization

\begin{tabular}{|c|c|c|c|}
\hline \multicolumn{4}{|c|}{ 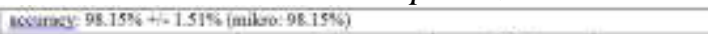 } \\
\hline & berpotent Bermanalah & $\begin{array}{c}\text { Trum } \\
\text { Tulak Bermanalah }\end{array}$ & Elan presisist \\
\hline Fed. BeFonenai Bermasalah & 119 & 4 & 96,754 \\
\hline Pred. Tidak Bermunalah & 2 & 200 & 99,016 \\
\hline clans reseill & $05.35 \%$ & os.04\% & \\
\hline
\end{tabular}
menggunakan nilai validasi dengan data original tersebut didapatkan nilai akurasi $98.15 \%$. Dan akurasi prediksi data berpotensi bermasalah $98,35 \%$ sedangkan tidak bermasalah hasil akurasinya 98,04\%.

Hasil perhitungan diatas dapat divisualisasikan dengan kurva ROC perbandingan kedua kelas bisa dilihat pada gambar 3.7 yang merupakan kurva ROC untuk optimasi algoritma C4.5 dan Particle Swarm Optimization dengan nilai validasi 6 . Garis horizontal adalah false positives dan garis vertikal adalah true positives. Menghasilkan nilai AUC (Area Under Curve) sebesar 0.739 dengan nilai akurasi cukup (fair classification) pada dataset kredit point siswa berpotensi bermasalah.

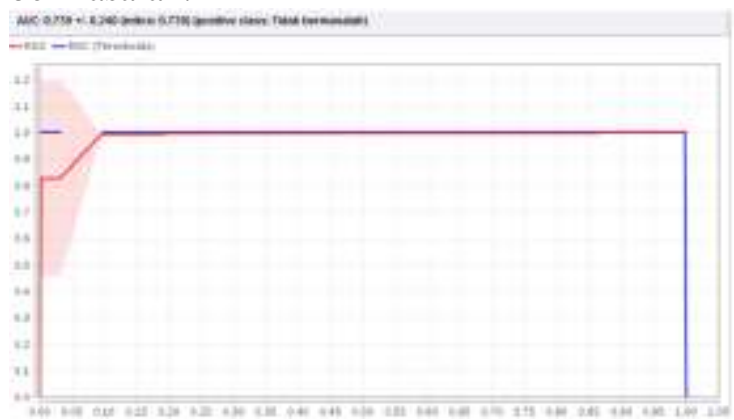

Gambar 3.7 Kurva AUC

\section{Hasil Optimasi C4.5 dan Particle Swarm Optimization Nilai Validasi 7}

Tahap kelimabelas pengujian dilakukan dengan data nomer akurasi validasi 7 . Ketika diimplementasikan menghasilkan data sebagai berikut : 
Tabel 3.17 Hasil Akurasi Optimasi C4.5 dan Particle Swarm Optimization

\begin{tabular}{|c|c|c|c|}
\hline & $\begin{array}{c}\text { fur } \\
\text { Aerpotens Betmasaiah }\end{array}$ & $\begin{array}{c}\text { True } \\
\text { Titak Bersianalid }\end{array}$ & clan pescisice \\
\hline FEed Hergonesait Bermasalah & its & 3 & 0.7 .4056 \\
\hline Pred Tidak Bermasalah & $\pi$ & Dी) & 97,106 \\
\hline das recoll & 95.0446 & 93.5346 & \\
\hline
\end{tabular}

Dari hasil pengujian pada tabel 3.17 menggunakan nilai validasi dengan data original tersebut didapatkan nilai akurasi $97.23 \%$. Dan akurasi prediksi data berpotensi bermasalah $85,04 \%$ sedangkan tidak bermasalah hasil akurasinya $98,53 \%$.

Hasil perhitungan diatas dapat divisualisasikan dengan kurva ROC perbandingan kedua kelas bisa dilihat pada gambar 3.8 yang merupakan kurva ROC untuk optimasi algoritma C4.5 dan Particle Swarm Optimization dengan nilai validasi 7 . Garis horizontal adalah false positives dan garis vertikal adalah true positives. Menghasilkan nilai AUC (Area Under Curve) sebesar 0.697 dengan nilai akurasi cukup (fair classification) pada dataset kredit point siswa berpotensi bermasalah.

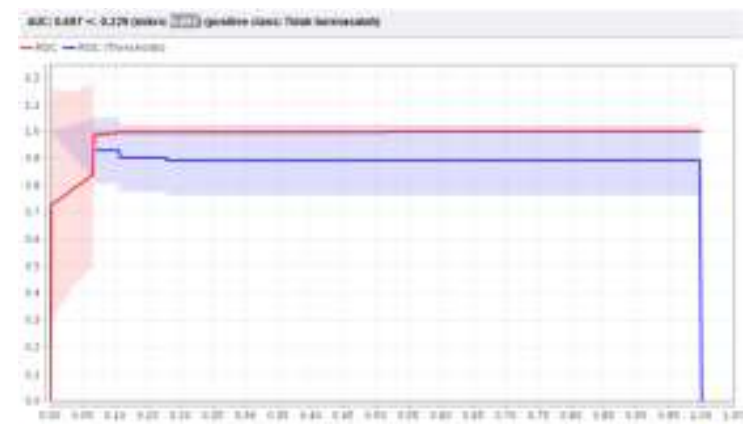

Gambar 3.8 Kurva AUC

\section{Hasil Optimasi C4.5 dan Particle Swarm Optimization Nilai Validasi 8}

Tahap keenambelas pengujian dilakukan dengan data nomer akurasi validasi 8 . Ketika diimplementasikan menghasilkan data sebagai berikut :

Tabel 3.18 Hasil Optimasi C4.5 dan Particle Swarm Optimization

\begin{tabular}{|c|c|c|c|}
\hline \multicolumn{4}{|c|}{ 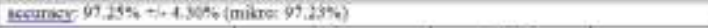 } \\
\hline & $\begin{array}{c}\text { true } \\
\text { berpotensi Beemasalin }\end{array}$ & $\begin{array}{c}\text { Irue } \\
\text { Thtak Dernanalak: }\end{array}$ & elass peceisioe \\
\hline perd Berposetsi Bemanalai & 115 & 3 & 97.4665 \\
\hline Pred, Fidak bermasala & 6 & 201 & $97.10 \%$ \\
\hline dan rexedil & $9500 \mathrm{~s}$ & 98.5366 & \\
\hline
\end{tabular}

Dari hasil pengujian pada tabel 3.18 menggunakan nilai validasi dengan data original tersebut didapatkan nilai akurasi $97.23 \%$. Dan akurasi prediksi data berpotensi bermasalah $95,04 \%$ sedangkan tidak bermasalah hasil akurasinya $98,53 \%$.
Hasil perhitungan diatas dapat divisualisasikan dengan kurva ROC perbandingan kedua kelas bisa dilihat pada gambar 3.9 yang merupakan kurva ROC untuk optimasi algoritma C4.5 dan Particle Swarm Optimization dengan nilai validasi 8. Garis horizontal adalah false positives dan garis vertikal adalah true positives. Menghasilkan nilai AUC (Area Under Curve) sebesar 0.662 dengan nilai akurasi cukup (fair classification) pada dataset kredit point siswa berpotensi bermasalah.

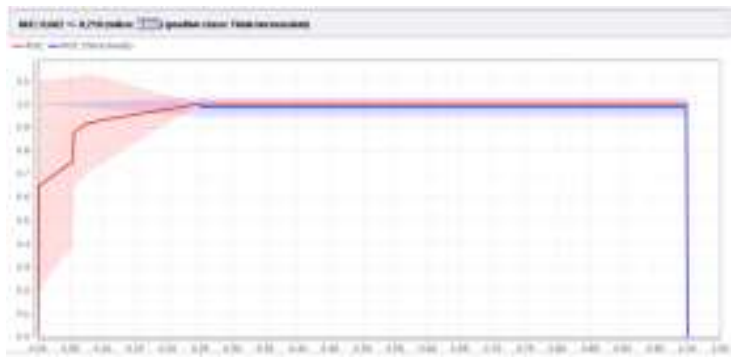

Gambar 3.9 Kurva AUC

\section{Hasil Optimasi C4.5 dan Particle Swarm Optimization Nilai Validasi 9}

Tahap ketujuhbelas pengujian dilakukan dengan data nomer akurasi validasi 9. Ketika diimplementasikan menghasilkan data sebagai berikut :

Tabel 3.19 Hasil Akurasi Optimasi C4.5 dan Particle Swarm Optimizatio

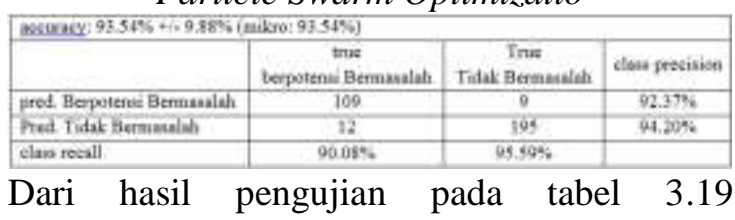
menggunakan nilai validasi dengan data original tersebut didapatkan nilai akurasi 93.54\%. Dan akurasi prediksi data berpotensi bermasalah $90,08 \%$ sedangkan tidak bermasalah hasil akurasinya $95,59 \%$.

Hasil perhitungan diatas dapat divisualisasikan dengan kurva ROC perbandingan kedua kelas bisa dilihat pada gambar 3.10 yang merupakan kurva ROC untuk optimasi algoritma C4.5 dan Particle Swarm Optimization dengan nilai validasi 9. Garis horizontal adalah false positives dan garis vertikal adalah true positives. Menghasilkan nilai AUC (Area Under Curve) sebesar 0.798 dengan nilai akurasi cukup (fair classification) pada dataset kredit point siswa berpotensi bermasalah. 


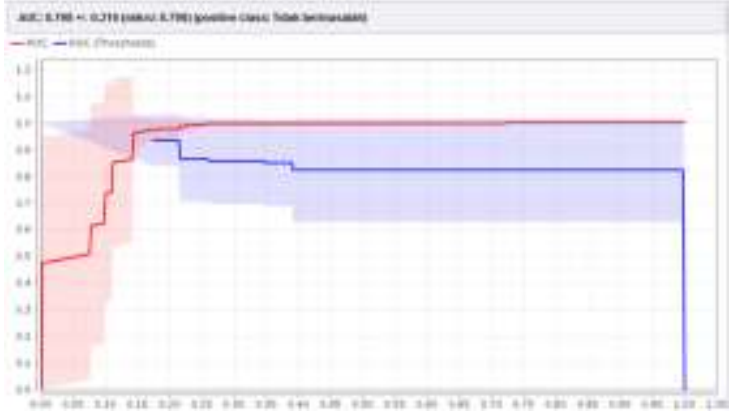

Gambar 4.10 Kurva AUC

\section{Hasil Optimasi C4.5 dan Particle Swarm Optimization Nilai Validasi 10}

Tahap kedelabanbelas pengujian dilakukan dengan data nomer akurasi validasi 10. Ketika diimplementasikan menghasilkan data sebagai berikut :

Tabel 3.20 Hasil Akurasi Optimasi C4.5 dan

Particle Swarm Optimization

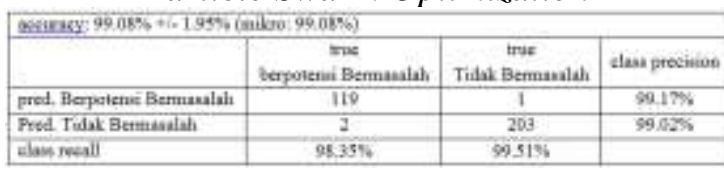

Dari hasil pengujian pada tabel 3.20 menggunakan nilai validasi dengan data original tersebut didapatkan nilai akurasi 99.08\%. Dan akurasi prediksi data berpotensi bermasalah $98,35 \%$ sedangkan tidak bermasalah hasil akurasinya $99,51 \%$.

Hasil perhitungan diatas dapat divisualisasikan dengan kurva ROC perbandingan kedua kelas bisa dilihat pada gambar 3.11 yang merupakan kurva ROC untuk optimasi algoritma C4.5 dan Particle Swarm Optimization dengan nilai validasi 10 . Garis horizontal adalah false positives dan garis vertikal adalah true positives. Menghasilkan nilai AUC (Area Under Curve) sebesar 0.500 dengan nilai akurasi cukup (fair classification) pada dataset kredit point siswa berpotensi bermasalah.

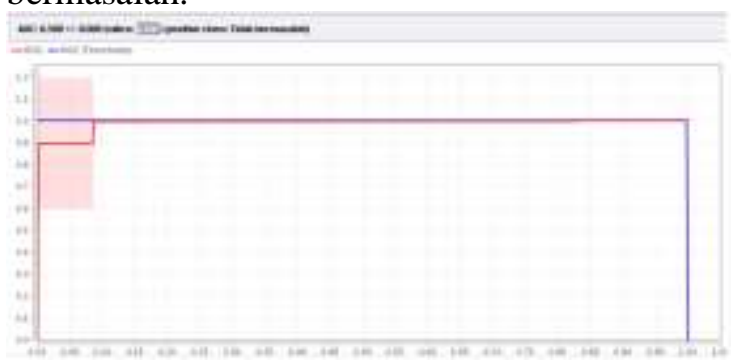

Gambar 3.11 Kurva AUC
Perbandingan C4.5 dengan optimasi C.4.5 dan Particle Swarm Optimization

Tabel 3.21 Perbandingan C4.5 dengan optimasi C4.5 dan Particle Swarm Optimization

\begin{tabular}{|c|c|c|}
\hline METODE & C4.5 & $\begin{array}{c}\text { Optimasi C4.5 dan Particie } \\
\text { Swarm Optimization }\end{array}$ \\
\hline Aceuracy & $63.35 \%$ & $99.08 \%$ \\
\hline Preciaion & $66.28 \%$ & $99.32 \%$ \\
\hline Recall & $84.50 \%$ & $99.51 \%$ \\
\hline AUC & 0.531 & 0.500 \\
\hline Time & & 52, \\
\hline
\end{tabular}

Dari tabel 3.21 dapat terlihat bahwa dengan menggunakan optimasi C4.5 dan Particle Swarm Optimization dapat meningkatkan hasil akurasi C4.5 dari 63,38 \% sampai dengan $99.08 \%$. Dapat dilihat jelas adanya kenaikan yang dihasilkan, kenaikannya cukup tinggi yaitu sebesar $35.7 \%$.

\section{Evaluasi dan Validasi Hasil}

Setelah melakukan pengujian metode algoritma C4.5 dengan menggunakan folds cross validation, kemudian dilihat hasil-hasil dari pengujian tersebut yang bisa kita lihat pada tabel 3.21 dapat disimpulkan metode C4.5 berbasis Particle Swarm Optimization memprediksi lebih akurat.

\section{Implementasi Penelitian}

Dengan adanya penerapan optimasi C4.5 dan Particle Swarm Optimization bisa memberikan solusi dan dapat membantu pihak terkait dalam hal untuk mengidentifikasi dan memprediksi siswa berpotensi bermasalah atau tidak bermasalah khususnya sekolah-sekolah lainnya.

\section{Kesimpulan}

Berdasarkan hasil pengujian klasifikasi dan pembahasan, maka diperoleh kesimpulan:

1. Optimasi Decision Tree C4.5 dan Particle Swarm Optimization menjadi lebih baik dalam memprediksi nilai akurasi dari menggunakan hanya metode C4.5 saja, yang mampu meningkatkan nilai akurasi cukup tinggi yaitu sebesar $35.7 \%$.

2. Optimasi Decision Tree C4.5 dapat diterapkan untuk prediksi siswa berpotensi bermasalah dengan tingkat akurasi 99,08\%. Dalam prediksi siswa berpotensi bermasalah, akurasi optimasi Algoritma C4.5 dan Particle Swarm Optimization 
lebih baik dari pada Algoritma decision Tree C.4.5 saja, dengan perbedaan yang cukup besar.

\section{Saran}

Berdasarkan kesimpulan di atas, maka ada beberapa saran yang dapat disampaikan :

1. Untuk menghasilkan prediksi yang lebih baik dan akurat penelitian berikutnya memerlukan data inputan yang lebih lengkap

2. Perbanyak pelatihan konfigurasi sehingga mendapatkan model yang menghasilkan error sekecil-kecilnya.

3. Dapat dikombinasikan dengan algoritma optimasi lain seperti Ant Colony Optimization (ACO), Adoboost, atau algoritma optimasi lainnya.

\section{Daftar Pustaka}

[1] Eklund Katie et al., "Early Identification of Behavioral and Emotional Problems in Youth: Universal screening versus Teacher-Referral Identification," The California School of Psychologist, vol. 14, pp. 89-95, 2009.

[2] Wallbro wn Amber Rae, "Concurrent and Predictive Validity of the Behavior and Emotional Screening System," Graduate College of Marshall University, Theses Paper 587, 2013.
[3] Drummond T, "The Student Risk Screening Scale (SRSS)," Josephine County Mental Health Program, Grants Pass - Oregon, 1994.

[4] Ulf Johansson, Henrik Boström, and Tuve Löfström, "Conformal Prediction Using Decision Trees," IEEE 2013, vol. 15504786/13, 2013.

[5] K Anuradha, Radha N Tulasi, and Kumar Pavan, "A Decision Tree Algorithm For Uncertain Data," International Journal of Engineering and Advanced Technology (IJEAT), vol. ISSN: 2249 - 8958 Volume1, no. 4, 2012.

[6] I H Witten and Eibe Frank, Data Mining : Practical Machine Learning Tools and Techniques Second Edition. San Francisco: Morgan Kauffman, 2005.

[7] W Yogi Yusuf, "Perbandingan Performance Algoritma Decision Tree C5.0, CART, Dan CHAID: Kasus Prediksi Status Resiko Kredit Di Bank $\mathrm{X}, "$ in Seminar Nasional Aplikasi Teknologi Informasi (SNATI 2007), Yogyakarta, 2007

[8] Rong Cao and Lizhen $\mathrm{Xu}$, "Improved C4.5 Algorithm for the Analysis of Sales," in 2009 Sixth Web Information Systems and Applications Conference, 2009. 